\title{
Assessing Pharmacy Practitioners' Perceptions of Continuing Pharmacy Education and Professional Development at an Oncology Service Hospital in Nepal: A Pilot Study
}

This article was published in the following Dove Press journal:

Advances in Medical Education and Practice

\author{
Baburam Adhikari' \\ Asmita Priyadarshini \\ Khatiwada $\mathbb{I D}^{2}$ \\ Ranish Shrestha $\mathbb{D D}^{3}$ \\ Sunil Shrestha $\mathbb{D}^{1}$ \\ 'Department of Pharmacy, Nepal Cancer \\ Hospital and Research Center, Lalitpur, \\ Nepal; ${ }^{2}$ Department of Pharmaceutical \\ and Health Service Research, Nepal \\ Health Research and Innovation \\ Foundation, Lalitpur, Nepal; ${ }^{3}$ Infection \\ Control Unit, Nepal Cancer Hospital and \\ Research Center, Lalitpur, Nepal
}

Introduction: Continuing pharmacy education (CPE) and continuing professional development (CPD) programs have been useful for enhancing the skills and performance of pharmacists. Despite its adoption worldwide, the practice of such programs has been limited in Nepal. The current pilot study aimed to assess the perception of pharmacists regarding $\mathrm{CPE} / \mathrm{CPD}$ in one of the oncology centers in Nepal. The goal of this study was to provide suggestions for developing and implementing the CPE/CPD programs.

Methods: This is a cross-sectional, questionnaire-based pilot study, whereby the pharmacists and assistant pharmacists at a single-center were provided with a structured questionnaire inquiring about their perception of $\mathrm{CPE} / \mathrm{CPD}$. A mixed-method approach was followed for data collection. Descriptive statistics were used for all the variables.

Results: A total of 15 pharmacy professionals were enrolled in the study. Recent innovations in pharmacy practices were the most commonly desired topics $(n=11,73.3 \%)$ for CPE/CPD. Live in-person presentations $(n=10,66.7 \%)$ and handouts method $(n=10,66.7 \%)$ were the most recommended practices for CPE/CPD. The most commonly cited deterrent was poor quality and method of CPE delivery $(n=11,73.3 \%)$, while the most common motivation was professional competence $(\mathrm{n}=12,80 \%)$.

Conclusion: This pilot study shows the benefits of developing CPE/CPD packages in future for pharmacy professionals focusing on advances in pharmacy practices and skill development, using in-person presentations and handouts, and focusing on the curiosity of the participant to improve his/her professional practice.

Keywords: continuing pharmacy education, continuing professional development, Nepal, pharmacist

\section{Introduction}

The role of pharmacists in the healthcare team is indispensable for obtaining desired patient outcomes; thus, they should be skilled at performing their tasks. As such, it is necessary to provide them with opportunities to continuously sharpen their knowledge, skills and practice, which can go beyond their formal education in terms of continuing pharmacy education (CPE) to enhance their professional competence. $^{1,2}$ Accreditation Council for Pharmacy Education (ACPE) defines $\mathrm{CPE}$ as a structured educational activity designed or intended to support the continuing development of pharmacists and/or pharmacy technicians to maintain
Correspondence: Asmita Priyadarshin Khatiwada

Department of Pharmaceutical and Health Service Research, Nepal Health Research and Innovation Foundation, Lalitpur, Nepal Email asmitapriyadarshinikhatiwada@gmail. com
Advances in Medical Education and Practice 2020:1/ 91 I-919 in $\bullet$ 
and enhance their competence. CPE should promote problem-solving and critical thinking and be applicable to the practice of pharmacy ${ }^{3} \mathrm{CPE}$ can be conducted using various methods including remote learning, lectures, workshops, printed handouts and audio recording. ${ }^{4}$ It tends to aid in promoting professional growth for pharmacists and improve medication usage in the community. ${ }^{5}$ However, CPE, which is limited to didactic learning methods and clinical knowledge and does not measure participants' competence or impact on patient care, may not lead to the desired result. These shortcomings can be overcome by integrating continuing professional development (CPD) into CPE. ${ }^{1}$

CPD is a concept focusing on enabling pharmacists and other healthcare professionals for continuous acquisition of knowledge. ${ }^{6}$ ACPE defines CPD as self-directed, ongoing, systematic and outcomes-focused approach to lifelong learning that is applied into practice. It involves the process of active participation in formal and informal learning activities that assist individuals in developing and maintaining continuing competence, enhancing their professional practice, and supporting achievement of their career goals. ${ }^{7} \mathrm{CPD}$ adds to but does not replace CPE and ensures that pharmacists improve their competency at providing care to patients. ${ }^{1}$ In countries like United States, Great Britain, Canada, Australia and New Zealand, CPD is already integrated into CPE systems and policies. ${ }^{7}$

The International Pharmaceutical Federation (FIP) recommends encouraging participation in CPE/CPD programs to enhance the capability of pharmacists. ${ }^{8}$ Pharmacists are in favour of CPD for professional growth and licensure, ${ }^{9}$ the desire to gain practical knowledge, to stay updated and experience a break from routine work. ${ }^{10,11}$ The importance of CPE/CPD is highlighted by the increase in the product- and patient-oriented pharmacy services ${ }^{7}$ and to remain updated on innovative, evidence-based practices. ${ }^{10}$ The approach towards CPE differs among nations around the world. ${ }^{8}$

In Nepal, the study of pharmacy is limited to programs including 3-year Diploma in Pharmacy (D. Pharm) under Council for Technical Education and Vocational Training (CTEVT), 4-year Bachelor's in Pharmacy (B.Pharm) and 2-years Master's in Pharmacy (Industrial pharmacy, pharmaceutical care and clinical pharmacy) under different universities. ${ }^{12}$ To work as apharmacy professional, after completion of Diploma or Bachelor degree, one should be registered in the Nepal Pharmacy Council (NPC), which conducts quarterly licensure exams for the registration process. ${ }^{13}$ Those who have completed D.Pharm and B. Pharm are considered assistant pharmacists and pharmacists, respectively. Those who have completed their Doctor of pharmacy (Pharm D, Post-Baccalaureate) or Master's in clinical pharmacy or Master's in pharmaceutical care working in the clinical settings are considered clinical pharmacist.

$\mathrm{CPE}$ is still in its embryonic phase in Nepal and has not been made mandatory in any setting. However, its importance and positive responses have been highlighted by different authors. ${ }^{14,15}$ Nepal Cancer Hospital and Research Center (NCHRC) is a tertiary cancer care center, with a dedicated pharmacy and team of professional pharmacists. The current study aimed to assess the perception of pharmacists regarding CPE/CPD in NCHRC to help provide suggestions to key leaders for developing and implementing CPE/CPD packages.

\section{Materials and Methods Study Design}

This cross-sectional descriptive, single-center study was carried out using a mixed-methods approach for the period of 3 months from October to December 2019.

\section{Study Site}

The study was conducted in the pharmacy department of the NCHRC in Lalitpur, Nepal. The treatments available in this hospital are chemotherapy, radiotherapy, surgery, targeted therapy, and immunotherapy. Approximately 3000 patients visit this hospital for the treatment of cancer annually.

\section{Study Sample}

All the pharmacists (with a four-year B. Pharm degree) and assistant pharmacists (with a three-year D. Pharm degree) working at NCHRC were enrolled in the study. Clinical pharmacists working in the hospital were excluded from this study.

\section{Ethical Approval}

Ethical approval from the Institutional Review Committee (Reg. no: IRC-NCHRC/008/2018) of Nepal Cancer Hospital and Research Center was obtained. Before collecting data from the participants, written informed consent was obtained from each participant. Privacy and confidentiality were maintained, ensuring that collected information was used only for the study purpose. 


\section{Data Collection Tool}

The tool for data collection was a questionnaire obtained from Poudel et al. ${ }^{14}$ The original questionnaire consisted of three sections which were modified, and the updated version of it is in Appendix 1. The changes in the original questionnaire are listed below:

- In Section 1, we have added two items, ie, "availability of computer/laptop in workplace/home" and "Have you ever attended CPE/CPD?"

- In Section 2, item motivating factors, "professional competence", were added as an option.

- In section 2, item-inhibiting factors, "Others (tiredness, uninteresting topics)" were removed and replaced with "Uninteresting topics only".

- In section 2, item evaluating the effectiveness, we have removed the option "others (quiz contest)".

- No changes were made in section 3. However, we have added one new more section, i.e., section 4 to explore the opinion of areas included in CPE content by participants.

The tool was administered in the English language (which was understandable, spoken and written well by all the enrolled participants). After the modification of the final questionnaire, it consisted of four sections.

Section 1 comprised seven items that explored the demographic characteristics and related information: age, gender, educational qualifications, working area, current position, work experience, availability of computer/laptop at workplace/home and previous attendance in CPE. Section 2 comprised six items that explored the opinion of participants toward the CPE program including topics that needed to be covered, methods, and motivating factors, inhibiting factors, preferred length and method for evaluating the effectiveness. The third section included the suggestions from participants for the improvement of CPE/CPD. The fourth section consists of open-ended questions which were added in this questionnaire to know the areas of interest of the participants in the study. Inductive approach of thematic content analysis was done to prepare section four, which is an addition to the questionnaire by Poudel et $\mathrm{al}^{14}$ The second, third and fourth sections of the questionnaire allowed multiple responses. The modified version of the questionnaire is available in Appendix 1.

\section{Data Collection Procedure}

The questionnaires were hand-delivered. The participants were approached by the principal investigator, and the aim of the study was explained. After obtaining written informed consent from all the enrolled participants, the modified questionnaire was distributed among them, and it was ensured that the questionnaire was filled in the presence of a member of the study team. This setup was chosen to ensure that the questionnaires were filled completely and to aid participants in resolving any doubts.

\section{Data Analysis}

Descriptive statistical tools such as mean, median, standard deviation, interquartile range (IQR) were calculated for the continuous variables, and frequency and percentage were calculated for categorical variables. Data from the openended questions were listed as categories and were summarized in frequency and percentage as well. Thematic content analysis was used to analyze the data generated from suggestions of participants for improving the $\mathrm{CPE} / \mathrm{CPD}$ program and perceptions of areas included in CPE content. All the statistical analyses were carried out by using the statistical package SPSS version 23 (SPSS Inc., Chicago, IL, USA).

\section{Results}

A total of 15 participants were included in this study. Table 1 defines the demographics, work experience and conditions of participants in the study. The average age of study participants was $25.67 \pm 2.46$ years, and the median (IQR) age was 26 (26-24) years. Almost half of the study population was male $(n=8,53.3 \%)$. The majority of pharmacy professionals held B. Pharm degree $(n=9,60 \%)$. An equal number of pharmacy professionals were working in both in- and outpatient pharmacy settings and exactly half the number in-store. Most of the study participants were working as assistant pharmacists $(n=11,73.3 \%)$. The mean working experience of the study population was $2.85 \pm 3.4$ years, and the median (IQR) was 1.33 (2.67-1) years. The majority of the pharmacy professionals had access to a desktop or laptop computer in the workplace or at home, and almost half of them $(n=8,53.3 \%)$ had already attended a CPE/CPD program earlier.

\section{Opinions of Participants Towards the CPE Program}

Table 2 describes the responses of participants towards various opinion questions regarding CPE/CPD. Most of the participants were interested int a $\mathrm{CPE} / \mathrm{CPD}$ about recent innovations in pharmacy practice $(n=11,73.3 \%$ ), followed by CPE/CPD on skills development $(\mathrm{n}=10,66.7 \%)$ and regulatory requirements $(n=4,26.7 \%)$. Live in-person presentation $(n=10$, 
Table I Socio-Demographic Characteristics of Participants

\begin{tabular}{|c|c|c|}
\hline $\begin{array}{l}\text { Socio Demographic } \\
\text { Characteristics }\end{array}$ & Number & Percentage \\
\hline \multicolumn{3}{|l|}{ Age } \\
\hline Mean & 25.67 & \\
\hline Median & 26.00 & \\
\hline St. deviation & 2.46 & \\
\hline IQR (Q3-QI) & $26-24$ & \\
\hline \multicolumn{3}{|l|}{ Gender } \\
\hline Male & 8 & 53.3 \\
\hline Female & 7 & 46.7 \\
\hline \multicolumn{3}{|l|}{ Educational qualifications } \\
\hline Diploma in Pharmacy & 6 & 40 \\
\hline Bachelor in Pharmacy & 9 & 60 \\
\hline \multicolumn{3}{|l|}{ Working area } \\
\hline Inpatient Pharmacy & 6 & 40 \\
\hline Outpatient Pharmacy & 6 & 40 \\
\hline Store and Bulk & 3 & 20 \\
\hline \multicolumn{3}{|l|}{ Current position } \\
\hline Assistant Pharmacist & 11 & 73.3 \\
\hline Pharmacist & 4 & 26.7 \\
\hline \multicolumn{3}{|l|}{ Working experience (in years) } \\
\hline Mean & 2.85 & \\
\hline Median & 1.33 & \\
\hline St. deviation & 3.4 & \\
\hline IQR (Q3-QI) & $(2.67-I)$ & \\
\hline \multicolumn{3}{|l|}{$\begin{array}{l}\text { Availability of computer/laptop in } \\
\text { workplace/home }\end{array}$} \\
\hline Yes & 12 & 80 \\
\hline No & 3 & 20 \\
\hline \multicolumn{3}{|l|}{ Have you ever attended CPE/CPD? } \\
\hline Yes & 8 & 53.3 \\
\hline No & 7 & 46.7 \\
\hline
\end{tabular}

$66.7 \%)$ and handouts $(\mathrm{n}=10,66.7 \%)$ were the most recommended methods of teaching. Professional competence $(\mathrm{n}=12$, $80 \%$ ) and curiosity about acquiring new scientific information $(\mathrm{n}=11,73.3 \%)$ were the primary motivations to participate in $\mathrm{CPE} / \mathrm{CPD}$ while poor quality of CPE delivery $(\mathrm{n}=11,73.3 \%)$ was the major inhibiting factor for participants. A training session of 3 hours $(n=10,66.7 \%)$ was the preferred time duration with a direct interview $(\mathrm{n}=10,66.7 \%)$ as the preferred method of evaluation.

\section{Suggestions of Participants for Improving the CPE/CPD Program}

Table 3 describes the suggestions from participants for the improvement of CPE where a single participant provided more than one suggestion. Compulsory CPD programs $(\mathrm{n}=9,60 \%)$, regular CPE/CPD sessions $(\mathrm{n}=8,53.3 \%)$, and qualified resource persons $(\mathrm{n}=6,40 \%)$ were suggested most frequently.

\section{Perceptions of Areas Included in CPE Content}

Table 4 describes the participants' perceptions regarding areas to be included in the CPE content. Thematic/content analysis was done and the responses from participants were categorized into five main themes. Five themes included - pharmacy skills, cancer diseases (trends, progression and new methods of management), pharmacy leadership and management, communication skills and clinical research methodology. Most participants wanted CPE training in pharmacy skills such as good dispensing practices $(n=14,93.9 \%)$, medication management $(n=13$, $86.7 \%)$, and cancer diseases $(\mathrm{n}=12,80 \%)$.

\section{Discussion}

This study assesses the perceptions of pharmacy practitioners regarding CPE/CPD while providing oncology service at an oncology center of Nepal.

The majority of the professionals in the current study held a B.Pharm degree $(n=9,60 \%)$ in contrast to the study conducted in Bharatpur, Chitwan. ${ }^{14}$ The increase in pharmacy colleges and rising number of pharmacy graduates with $\mathrm{B}$. Pharm degrees could be the reason for this disparity. CPE/ CPD on skills development and innovations in pharmacy practice was the commonly desired topic in this study, similar to the results of a single-center study conducted in a tertiary hospital in Bharatpur, Nepal. ${ }^{14}$ With constant advancements in the field of pharmacy globally, pharmacy practitioners feel the need to be updated with innovations to improve their skills for better results. This result is in alignment with the current ongoing practice of patient counselling and briefing on the use of inhalers by the community and institutional pharmacists, drug reviews by institutional pharmacists, medication record-keeping and reduction of prescription errors by pharmacy practitioners in Nepal, all of which necessitate skill development and being updated with innovations. ${ }^{14-16}$ A study in Belgium identified the issues relevant to day-today pharmacy practice as being the most interesting topics for community pharmacists. ${ }^{17}$ In another study, topics related to pharmaceutical care were the most desired ones by Flemish community pharmacists. ${ }^{11}$ 
Table 2 Opinion of Participants Toward the CPE Program

\begin{tabular}{|c|c|c|c|}
\hline Questions & Responses of Participants & $\begin{array}{l}\text { Number of Responses } \\
\text { from Participants (n) } \\
{[\mathrm{N}=15]}\end{array}$ & $\%$ \\
\hline \multirow{5}{*}{$\begin{array}{l}\text { Topics need to be covered in continuing } \\
\text { pharmacy education (CPE)/continuing } \\
\text { professional development (CPD) }\end{array}$} & Related to recent innovations in Pharmacy Practice & 11 & $73.3 \%$ \\
\hline & Related to skills development & 10 & $66.7 \%$ \\
\hline & Related to regulatory requirements & 4 & $26.7 \%$ \\
\hline & Related to disease management & 3 & $20 \%$ \\
\hline & Other topics for CPE/CPD & 1 & $6.7 \%$ \\
\hline \multirow[t]{5}{*}{ Methods suitable for CPE/CPD Program } & Live in-person presentation method & 10 & $66.7 \%$ \\
\hline & Audio and video method & 8 & $53.3 \%$ \\
\hline & Printed materials/handout method & 10 & $66.7 \%$ \\
\hline & Small group discussion method & 5 & $33.3 \%$ \\
\hline & Online information & 4 & $26.7 \%$ \\
\hline \multirow[t]{7}{*}{ Motivating factors for CPE/CPD } & Improve knowledge/skills & 9 & $60 \%$ \\
\hline & Professional Competence & 12 & $80 \%$ \\
\hline & Keeping up to date with the latest information & 6 & $40 \%$ \\
\hline & Job satisfaction & 4 & $26.7 \%$ \\
\hline & Requirement for promotion & 3 & $20 \%$ \\
\hline & Assist various needs for patients & 8 & $53.3 \%$ \\
\hline & Curiosity about getting new scientific information & 11 & $73.3 \%$ \\
\hline \multirow[t]{5}{*}{ Inhibiting factor for CPE/CPD } & Lack of time & 9 & $60 \%$ \\
\hline & Uninteresting topics & 6 & $40 \%$ \\
\hline & Poor quality and method of CE delivery & 11 & $73.3 \%$ \\
\hline & Cost & 3 & $20 \%$ \\
\hline & Conflict of interest & 5 & $33.3 \%$ \\
\hline \multirow[t]{2}{*}{ Preferred length of CPE/CPD } & 3 hours & 10 & $66.7 \%$ \\
\hline & 6 hours & 5 & $33.3 \%$ \\
\hline \multirow{4}{*}{$\begin{array}{l}\text { Method for evaluating the effectiveness of CPE/ } \\
\text { CPD }\end{array}$} & Practical exam & 9 & $60 \%$ \\
\hline & Written exam & 6 & $40 \%$ \\
\hline & Face-to-face interview & 10 & $66.7 \%$ \\
\hline & Feedback & 7 & $46.7 \%$ \\
\hline
\end{tabular}

Both live, in-person presentations and distribution of printed materials/handouts were recommended methods for CPE/CPD by the study participants. This finding was in line with a study conducted in Belgium regarding continuing education (CE) for community pharmacists, who preferred the provision of live courses and course notes ${ }^{17}$ and another study that concluded the preference towards face-to-face training. ${ }^{18}$ The live, in-person session was the preferred learning method because it allows the instructor to interact actively with the pharmacists and to provide immediate feedback. ${ }^{17,19}$ 
Table 3 Suggestions of Participants for Improving the CPE/CPD Program

\begin{tabular}{|c|c|c|}
\hline $\begin{array}{l}\text { Suggestions from } \\
\text { Participants }\end{array}$ & $\begin{array}{l}\text { Number of Responses } \\
\text { from Participants (n) } \\
{[\mathrm{N}=\mid 5]}\end{array}$ & $\%$ \\
\hline Compulsory CPD Programs & 9 & $60 \%$ \\
\hline $\begin{array}{l}\text { Conduction of such CPE/CPD } \\
\text { regular basis (Monthly) }\end{array}$ & 8 & $53.3 \%$ \\
\hline $\begin{array}{l}\text { Qualified International and } \\
\text { national resource persons for } \\
\text { CPE/CPD }\end{array}$ & 6 & $40 \%$ \\
\hline $\begin{array}{l}\text { Allocation of time for CPE/ } \\
\text { CPD Program }\end{array}$ & 6 & $40 \%$ \\
\hline $\begin{array}{l}\text { Accessibility of group learning } \\
\text { activities (location/distance) }\end{array}$ & 4 & $26.7 \%$ \\
\hline Cost should be free & 4 & $26.7 \%$ \\
\hline $\begin{array}{l}\text { Related to adverse drug } \\
\text { reaction management }\end{array}$ & 3 & $20 \%$ \\
\hline Include interesting topics & 3 & $20 \%$ \\
\hline $\begin{array}{l}\text { Motivation from hospital } \\
\text { management }\end{array}$ & 3 & $20 \%$ \\
\hline $\begin{array}{l}\text { More training on } \\
\text { Chemotherapy agents } \\
\text { especially Immunotherapy }\end{array}$ & 2 & $4 \%$ \\
\hline Practical based & 2 & $4 \%$ \\
\hline
\end{tabular}

Maintaining professional competence was observed to be the most common motivation among pharmacy professionals to attend a CPE/CPD program, followed by a curiosity for novel scientific information. Similar results have been observed in the Flemish study, in which the prime intention for participation in CPE was gathering practical knowledge and keeping the scientific knowledge up to standard, ${ }^{11}$ and in other studies where the motivation was to improve skills and keep up with novel information. ${ }^{14}$

According to the participants, the primary inhibiting factors towards CPE/CPD were the poor quality and method of $\mathrm{CE}$ delivery and lack of time. Time deficit, uninteresting subjects, family constraints, distance to classes, poor timing, excessive workload, inaccessibility, and irrelevance of content were the commonly reported barriers for participating in the CPE in different countries. ${ }^{11,14,19-22}$ A study in Nepal suggested a separate allocation of timings for CPE to overcome time constraints. ${ }^{14}$
Table 4 Perception of Areas Included in CPE Content

\begin{tabular}{|c|c|c|c|}
\hline \multicolumn{2}{|c|}{ Areas to be Included } & $\begin{array}{l}\text { Number of } \\
\text { Responses from } \\
\text { Participants (n) } \\
{[\mathrm{N}=\text { I5] }}\end{array}$ & $\%$ \\
\hline \multirow[t]{4}{*}{$\begin{array}{l}\text { Pharmacy } \\
\text { skills }\end{array}$} & $\begin{array}{l}\text { Medication } \\
\text { management }\end{array}$ & 13 & $86.7 \%$ \\
\hline & $\begin{array}{l}\text { Good dispensing } \\
\text { practice }\end{array}$ & 14 & $93.3 \%$ \\
\hline & $\begin{array}{l}\text { Pharmacovigilance } \\
\text { and adverse drug } \\
\text { reactions }\end{array}$ & 6 & $40 \%$ \\
\hline & $\begin{array}{l}\text { Emergency drug } \\
\text { management }\end{array}$ & 6 & $40 \%$ \\
\hline \multicolumn{2}{|c|}{$\begin{array}{l}\text { Cancer diseases (trends, } \\
\text { progression and new methods of } \\
\text { management) }\end{array}$} & 12 & $80 \%$ \\
\hline \multicolumn{2}{|c|}{$\begin{array}{l}\text { Pharmacy leadership and } \\
\text { management }\end{array}$} & 10 & $66.7 \%$ \\
\hline \multicolumn{2}{|c|}{ Communication skills } & 10 & $66.7 \%$ \\
\hline \multicolumn{2}{|c|}{ Clinical research methodology } & I & $6.7 \%$ \\
\hline
\end{tabular}

A duration of 3 hours per month was the preferred length for CPE/CPD by the study participants with faceto-face interviews as the widely accepted method for evaluating the effectiveness of the program. A study in Texas determined the desired duration of a CE program to be one to 2 hours. ${ }^{23}$ A study conducted in a hospital pharmacy in Nepal determined the desired duration of a CPE program to be more than 6 hours per month with the face-to-face interview as the preferred method of evaluation. ${ }^{14}$ Optimum duration of CPE/CPD program is essential to ensure attention and to fulfil the ultimate goals of the CPE program.

Participants of the study suggested conducting compulsory, monthly CPD programs to improve $\mathrm{CPE} / \mathrm{CPD}$ program. A mandatory system of CE and CPD programs has been successful in countries like the United Kingdom, Canada and New Zealand. ${ }^{17}$ Mandatory and regular CPE will accustom pharmacists to such programs, thus, helping improve the professional growth of pharmacy practitioners. However, making CPE compulsory might make pharmacists feel that their freedom being circumscribed. The freedom of pharmacy practitioners in the field should also be considered while designing CPE to promote its outcomes. 
The study participants mostly desired pharmacy skills, good dispensing practice, medication management, and trends, progression, and new methods for the management of cancer diseases to be covered in a CPE program. The inclusion of the hospital pharmacists only from an oncology hospital might have impacted these results.

This single-centered study is preliminary research towards obtaining an idea on what the views and perception of the pharmacists are about the CPE/CPD. Among a few studies in this field, this is the only one conducted in an oncology setting. This study provides additional evidence to the existing literature from Nepal that supports CPE/CPD for pharmacists for their professional growth. However, challenges like time constraints and poor quality of CPE need to be overcome. CPE/ CPD programs may be planned by considering individualized requirements such as alternative means to overcome missed content due to time constraint.

The CPE/CPD can be scheduled in separate allocated time as per the feasibility of the pharmacy professionals to make sure all of them attend the CPE/CPD programs and are benefitted from it. Once the program has been started within the institution, timely assessment should be carried out in order to assess the impact of the program on the practice of pharmacy professionals.

The content of the CPE programs should be updated based on the recent trends in medication management, and skills for good dispensing. Also, the content should be designed to be appealing and comprehensible to the attendees of the programs.

The findings of the study would be useful in planning a survey with a broader range of pharmacy professionals working in different institutions and healthcare settings throughout the nation. A greater number of participants may provide more explicit ideas on the ways of developing and implementing CPE. Also, it may aid in developing and implementing policies for making CPE mandatory throughout the country and if not possible, wherever feasible. The feasibility study may also be conducted beforehand planning for CPE programs at the respective sites. For effective CPE programs in Nepal, the ways to overcome the challenges, desired content and delivery methods of the CPE identified in this study can be considered along with the collaborative initiatives by the authorities from the government level and the local level. Also, an interventional study by providing CPE for a specific time and assessing the response afterwards, involving a mix of qualitative and quantitative data can be conducted.

\section{Limitations}

This is a pilot study with a smaller number of study participants. So, the data may not be generalized. The observations with a smaller number of participants hinder to draw an effective adequate and practical conclusion from this study. Selection bias may be a limitation of this study as it focuses on pharmacists from a single institution. Clinical pharmacists working at the hospital were also excluded in this study as we only focused on the pharmacists and assistant pharmacists working at the hospital pharmacy. The study was more qualitative rather than quantitative, which limits the understanding of the perception of pharmacy professionals. As the questionnaire was filled in the presence of a team member, there might be information bias as well.

\section{Conclusion}

From this study, it can be concluded that the professional pharmacists understand the importance of and thus, require $\mathrm{CPE}$ and $\mathrm{CPE} / \mathrm{CPD}$ programs while incorporating recent innovations, such as good dispensing practices, in pharmacy practices can be a way to encourage them to participate. Live, in-person presentations and handouts are preferred methods of teaching, while a direct interview is the preferred evaluation method. The incorporation of these findings can improve the quality of the CPE and ultimately, the patient care services by the pharmacists. In a country like Nepal, where the concept of CPE/CPD is still in its nascent form, national and local authorized bodies like NPC are recommended to aid in pharmacy services' improvement via incorporating such programs within their professional frameworks.

\section{Abbreviations}

$\mathrm{CPE}$, continuing pharmacy education: $\mathrm{CPD}$, continuing professional development: CE, continuing education; ACPE, Accreditation Council for Pharmacy Education; FIP, International Pharmaceutical Federation; NCHRC, Nepal Cancer Hospital and Research Centre; IQR, inter-quartile range.

\section{Data Sharing Statement}

The datasets used in the current study are available from the corresponding author on a reasonable request.

\section{Ethical Approval}

Ethical approval from the Institutional Review Committee (Reg.no: IRC-NCHRC/008/2018) of Nepal Cancer Hospital and Research Center was obtained. 


\section{Consent to Participate}

Written informed consent was obtained from all individual participants included in the study.

\section{Consent for Publication}

Written informed consent from study participants was obtained for publication.

\section{Acknowledgments}

The author(s) would like to acknowledge all the participants involved in this study. The author(s) would like to acknowledge, Mr. Ramesh Sharma Poudel and Professor. Dr Rano Mal Piryani for providing a questionnaire to use in the study.

\section{Author Contributions}

All authors made substantial contributions to conception and design, acquisition of data, or analysis and interpretation of data; took part in drafting the article or revising it critically for important intellectual content; agreed to submit to the current journal; gave final approval of the version to be published; and agree to be accountable for all aspects of the work.

\section{Funding}

This research did not receive any funding from any agency in the public, commercial, or not-for-profit sectors.

\section{Disclosure}

The authors declare that they have no competing interests.

\section{References}

1. Wheeler JS, Chisholm-Burns M. The benefit of continuing professional development for continuing pharmacy education. Am J Pharm Educ. 2018;82(3):6461. doi:10.5688/ajpe6461

2. Janke KK, Tofade T. Making a curricular commitment to continuing professional development in doctor of pharmacy programs. Am J Pharm Educ. 2015;79(8):112. doi:10.5688/ajpe798112

3. ACPE. Accreditation Council for Pharmacy Education Definition of Continuing Education for the Profession of Pharmacy; 2015. Available from: https :// ww w a c pe-accredit.org/pdf/ DefinitionContinuingEducationProfession\%20Pharmacy2015.pdf. Accessed September 9, 2020.

4. Aldosari H, Alsairafi Z, Waheedi S. Continuing education in pharmacy: a cross-sectional study exploring pharmacists' attitudes and perceptions. Saudi Pharm J. 2020;28(7):803-813. doi:10.1016/j.jsps.2020.05.008

5. Durai R, Swaminathan KK, Alam Krishnamoorthy SS, et al. Continuing pharmacy education: effect on knowledge, attitude and practice of community pharmacists in South India. Indian J Pharm Pract. 2016;9(3):195. doi:10.5530/ijopp.9.3.11
6. Tsoi SLTA, de Boer A, Croiset G, Kusurkar RA, Koster AS. A longitudinal approach to changes in the motivation of Dutch pharmacists in the current continuing education system. $\mathrm{Am}$ J Pharm Educ. 2018;82(2):6199.

7. Vaidya A, Pathak RP, Pandey MR. Prevalence of hypertension in Nepalese community triples in 25 years: a repeat cross-sectional study in rural Kathmandu. Indian Heart J. 2012;64(2):128-131. doi:10.1016/S0019-4832(12)60045-5

8. FIP. Continuing Professional Development/Continuing Education in Pharmacy: Global Report; 2014. The Hague, The Netherlands: International Pharmaceutical Federation. Available from: https:// www.fip.org/file/1407. Accessed September 8, 2020.

9. Ang H-G, Pua Y-H, Subari NA. Mandatory continuing professional education in pharmacy: the Singapore experience. Int J Clin Pharm. 2013;35(4):570-576. doi:10.1007/s11096-013-9767-y

10. Hanson AL, Bruskiewitz RH, DeMuth JE. Pharmacists' perceptions of facilitators and barriers to lifelong learning. Am J Pharm Educ. 2007;71(4):67. doi:10.5688/aj710467

11. Driesen A, Leemans L, Baert H, Laekeman G. Flemish community pharmacists' motivation and views related to continuing education. Pharm World Sci. 2005;27(6):447-452. doi:10.1007/s11096-005-0950-7

12. Shrestha S, Shakya D, Palaian S. Clinical pharmacy education and practice in Nepal: a glimpse into present challenges and potential solutions. Adv Med Educ Pract. 2020;11:541-548. doi:10.2147/AMEP.S257351

13. Bhandari B, Bhattarai M, Bhandari M, Ghimire A, Pokharel PK, Morisky DE. Adherence to antihypertensive medications: population based follow up in Eastern Nepal. J Nepal Health Res Counc. 2015;13(29):38-42.

14. Poudel RS, Piryani RM, Shrestha S, Chaurasiya R, Niure BP. Opinion of hospital pharmacy practitioners toward the continuing pharmacy education program: a study from a tertiary care hospital in central Nepal. Integr Pharm Res Pract. 2017;6:157-161. doi:10.2147/IPRP.S145026

15. Poudel A, Khanal S, Alam K, Palaian S. Perception of Nepalese community pharmacists towards patient counseling and continuing pharmacy education program: a multicentric study. J Clin Diagn Res. 2009;3(2):1408-1413.

16. Mishra P, Subish P, Upadhyay D, Bista S, Alam K, Bhandari R. Medication counseling center in a teaching hospital. JNMA J Nepal Med Assoc. 2005;44(160):129-134.

17. Driesen A, Airaksinen M, Simoens S, Laekeman G. What if continuing education became mandatory? Opinions of Belgian community pharmacists. Int J Pharm Pract. 2007;15(1):61-68. doi:10.1211/ ijpp.15.1.0010

18. Schindel TJ, Kehrer JP, Yuksel N, Hughes CA. University-based continuing education for pharmacists. Am J Pharm Educ. 2012;76 (2):20. doi:10.5688/ajpe 76220

19. Wilbur K. Continuing professional pharmacy development needs assessment of Qatar pharmacists. Int J Pharm Pract. 2010;18 (4):236-241. doi:10.1111/j.2042-7174.2010.00034.x

20. Marriott JL, Duncan GJ, Namara KPM. Barriers to pharmacist participation in continuing education in Australia. Pharm Educ. 2007;7 (1):11-17. doi:10.1080/15602210601084176

21. Iskandar K, Raad EB, Hallit S, et al. Assessing the perceptions of pharmacists working in Lebanese hospitals on the continuing education preferences. Pharm Pract (Granada). 2018;16(2):1159.

22. Sacre H, Tawil S, Hallit S, Sili G, Salameh P. Mandatory continuing education for pharmacists in a developing country: assessment of a three-year cycle. Pharm Pract (Granada). 2019;17(3):1545.

23. Alkateeb FM, Attarabeen OF, Alameddine S. Assessment of Texan pharmacists' attitudes, behaviors, and preferences related to continuing pharmacy education. Pharm Pract (Granada). 2016;14(3):769. 


\section{Publish your work in this journal}

Advances in Medical Education and Practice is an international, peerreviewed, open access journal that aims to present and publish research

on Medical Education covering medical, dental, nursing and allied health care professional education. The journal covers undergraduate education, postgraduate training and continuing medical education including emerging trends and innovative models linking education, research, and health care services. The manuscript management system is completely online and includes a very quick and fair peer-review system. Visit http://www.dovepress.com/testimonials.php to read real quotes from published authors.

Submit your manuscript here: http://www.dovepress.com/advances-in-medical-education-and-practice-journal 